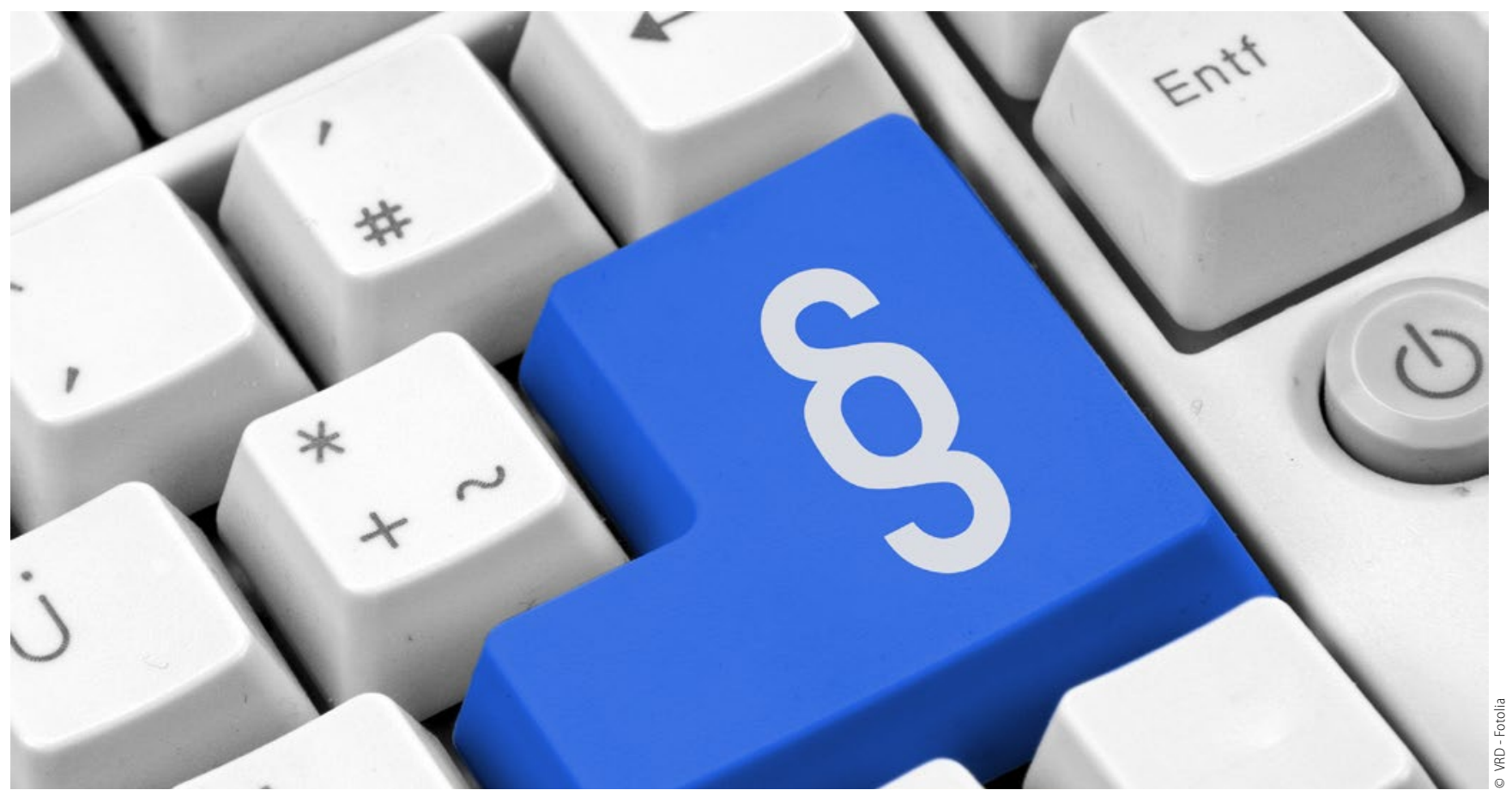

Kritik auf breiter Front

\title{
Sachverständige lehnen Selbstverwaltungsstärkungsgesetz ab
}

Es ist ein Gesetz, das kaum Freunde hat: das GKV-Selbstverwaltungsstärkungsgesetz. Dies wurde bei der öffentlichen Anhörung der Sachverständigen im Bundestagsausschuss für Gesundheit Mitte Januar in Berlin überdeutlich. Der Name des Gesetzes sei mindestens irreführend, hieß es bei den Kritikern, denn im Kern führe es nicht zu einer Stärkung der Selbstverwaltung und mehr Transparenz, wie dies ursprünglich geplant gewesen sei, sondern zu einer Schwächung durch mehr Kontrolle und weitreichende staatliche Durchgriffsrechte.

Neben Fragen zu den Kontrollrechten des aufsichtsführenden Bundesministeriums für Gesundheit (BMG), aus dessen Haus auch die ursprüngliche Vorlage des Gesetzentwurfes stammt, wollten sich die Mitglieder des Gesundheitsausschusses auch über geplante Sanktions- und Aufsichtsmaßnahmen bei den Sachverständigen der Selbstverwaltungen und Verbänden sowie den unabhängigen Experten informieren, die zu der Anhörung eingeladen waren. Deutlich wurde in den Antworten der Expertenrunde und den Spitzen der betroffenen Selbstverwaltungsorgane: Sie alle sehen in dem Gesetz eine Strafmaßnahme der Politik für die Verfehlungen, die in einer einzelnen Organisation passiert sind. Unregelmäßigkeiten und Missstände bei der Kassenärztlichen Bundesvereinigung (KBV), die bereits Jahre zurückliegen, hatte das BMG im Sommer 2016 dazu veranlasst, das Gesetz in dieser Härte zu formulieren, um „künftige Kompetenzüberschreitungen“ zu vermeiden, wie es hieß.

\section{Mehr Kontrolle, keine Differenzierung}

Kritisiert wird nun vorwiegend, dass der Gesetzgeber mit der Verschärfung von Kontrolle und Aufsicht keine Differenzierung zwischen den Selbstverwaltungen macht, die bisher nie Anlass zu Be- anstandungen für die Aufsicht geboten hätten. Dies betonten die Vertreter der Kassenzahnärztlichen Bundesvereinigung ebenso wie die des Spitzenverbandes der gesetzlichen Krankenkassen und des Gemeinsamen Bundesausschusses. Dass das Gesetz nun alle Bereiche der Selbstverwaltung im Gesundheitsbereich trifft, ist den Beteiligten ein Dorn im Auge. Das BMG allerdings betont: Eine „Lex KBV“ sei nicht möglich gewesen. Auf die Verfehlungen des ehemaligen KBV-Vorstands im Ausschuss angesprochen, antwortete der heutige KBV-Chef Andreas Gassen knapp: „Individuelle Fehler passieren, diese muss man auch korrigieren, allerdings sind sie nicht per se zu verhindern."

Durch die Anhörung und die breite Front der Ablehnung scheint nun jedoch noch einmal Bewegung in die Sache zu kommen. Auch der Freie Verband Deutscher Zahnärzte (FVDZ) warnt nachdrücklich vor überzogenen Eingriffen in die Autonomie des zahnärztlichen Berufsstandes durch das Gesetz. Anlässlich der Anhörung im Gesundheitsausschuss erklärte der FVDZ-Bundesvorsitzende Harald Schrader: „Das geplante Gesetz greift fundamental in die Handlungsspielräume der Selbstverwaltungsorgane ein. Dies kann nicht im Sinne der Funktionstüchtigkeit eines gewachsenen Systems sein." Wenn das Gesetz schon nicht ganz aus der Welt zu schaffen sei, fordert der FVDZ vom Gesetzgeber zumindest ein gestuftes Verfahren. „Vor der externen Kontrolle durch den Staat sollte die Verantwortung in die Hände der Selbstverwaltung gelegt werden “, appellierte Schrader. Stärkere Kontrollrechte für die Mitglieder der Selbstverwaltungsorgane in Verbindung mit abgestufter aufsichtsrechtlicher Kontrolle seien der bessere Weg, um die Handlungsfähigkeit der Berufsorganisationen zu stärken. Endgültig entscheiden über das Gesetz wollen die Bundestagsabgeordneten voraussichtlich Mitte Februar. 